\title{
Comparison of Performance of Various Leaf Spring Material used in Automotive Industry
}

\author{
Dr. Amit Pradhan \\ Asst Professor, Mechanical Engineering Deptt. Technocrats Institute of Technology Advance Bhopal (M.P.) India
}

\author{
Yogendra Rathore \\ H.O.D., Mechanical Engineering Deptt. Govt.Polytechnic College, Raisen,(M.P.)India
}

\begin{abstract}
Among different types of springs commonly used in automotive industry leaf spring is one of the common types. These consist of narrow plates of different types and sizes. These are usually thick in middle and tapered outward at the end .these don't provide too much strength and suspension to the vehicles .drivers use these multiple leaf springs to tow heavier loads at the end of the vehicles. Which consist of various leaf springs of varying lengths in line at the top of each other. The shorter the leaf spring closer to the bottom it will be giving it the same semielliptical shape a single leaf spring gets from being thicker in the middle. The design dimensions of the existing convention leaf spring are taken. Same dimension of the conventional leaf spring are used to fabricate a leaf spring using the composite materials. The main objective of this paper is to compare the load carrying capacity, stiffness and weight saving of the composite leaf spring for which the Catia V5 software is used for modeling and analysis is performed using ANSYS.
\end{abstract}

Keywords:-Computer aided engineering (CAE), Finite element analysis, Composite materials, Parabolic leaf spring.

\section{INTRODUCTION}

The suspension leaf spring is one of the potential items for weight reduction in automobiles as it accounts for $10 \%$ $20 \%$ of the unstrung weight. This achieves the vehicle with more fuel efficiency and improved riding qualities. The introduction of composite materials was made it possible to reduce the weight of leaf spring without any reduction on load carrying capacity and stiffness.

Also Reduction in weight while increasing or maintaining strength of products is becoming more important for the researchers and automotive experts to sustain in the prevailing circumstances where light weighted vehicles are more likely preferred by the today's generation.

For which Composite materials are one of the families of material which are attracting researchers and giving solutions of such issues. In order to conserve natural resources and economic, energy, weight reduction has been the main focus of automobile manufactures. In the present scenario weight reduction can be achieved primarily by the introduction of better material.

The Leaf spring is one of the potential group of parts for weight reduction in automobiles as it accounts for $10 \%$ $20 \%$ of the unstrung weight. This provides vehicle with more fuel efficiency and improved riding qualities. After the introduction of composite materials it has been made possible to reduce the weight of leaf spring without any reduction of load carrying capacity and stiffness.

Leaf spring should absorb vertical vibration and impacts due to load irregularities by means of variation in the spring deflection show that potential energy is stored in spring as strain energy and then release slowly so, increasing energy stored capability of a leaf spring insure a more complaint suspension system.

The large vehicle needs a good suspension system that can be delivered a good ride and handling. At the same time that component need to be light weight and had an excellent of fatigue life.

Most of researches focused on improving fatigue resistance by shoot penning process, making the nucleation and propagation of fatigue cracks difficult. Few publication, which are listed in references attempted predictions of fatigue life from stress approach model. 


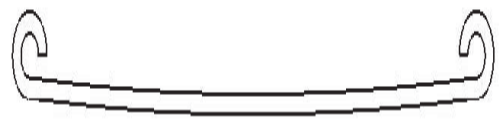

Leaf Spring View

TOOL (Modeling \& Analysis)

ANSYS is engineering analysis software used for general purpose like finite element Analysis for finding the approximate numerically solving of mechanical problems. Here ANSYS 14 is used for analyzing the performance of conventional and composite leaf spring. Leaf spring is modeled in Catia V5 R20 software and it is imported in ANSYS 14.0. The conventional steel leaf spring and the composite leaf spring were analyzed under similar conditions using ANSYS software.

In this section the conventional steel and composite parabolic leaf spring will be analyzed to see the various results from the static analyses. The software used to perform the analysis is ANSYS 14. ANSYS software is used to analyze the stresses by performing static analysis for the given leaf spring specification and to determine the stiffness in leaf springs.

\section{II.I. MATERIAL PROPERTIES}

\section{SELECTION OF MATERIAL}

There are Two leaf springs on which the analyses are going to perform, one is conventional steel leaf spring and other three are composite leaf springs. The properties of the conventional steel material 55Si2 Mn90 [18] being used in this analysis are shown in Table-1

Table 1: Composition of various elements in 55Si2Mn90

\begin{tabular}{|c|c|c|c|c|c|c|c|}
\hline Grade & $\mathbf{C} \%$ & $\mathbf{S i} \%$ & $\mathbf{M n} \%$ & $\mathbf{C r} \%$ & $\mathbf{M o} \%$ & $\mathbf{P \%}$ & $\mathbf{S \%}$ \\
\hline $55 \mathrm{Si} 2 \mathrm{Mn} 90$ & 0.55 & 1.74 & 0.87 & 0.1 & 0.02 & 0.05 & 0.05 \\
\hline
\end{tabular}

Table 2: Material Properties of existing PLS (55Si2Mn90)

\begin{tabular}{|c|c|}
\hline PARAMETER & VALUE \\
\hline Young's Modulus (E) & $200 \mathrm{GPa}$ \\
\hline Poisson's Ratio & 0.3 \\
\hline Tensile Strength Ultimate & $1962 \mathrm{MPa}$ \\
\hline Tensile Strength Yield & $1500 \mathrm{MPa}$ \\
\hline Density & $7850 \mathrm{~kg} / \mathrm{m} 3$ \\
\hline Thermal Expansion & $11 \times 10-6 /{ }^{\circ} \mathrm{C}$ \\
\hline
\end{tabular}

Table 2: Shows the mechanical properties of composite (E-Glass/Epoxy) material, which can be taken as per Ansys Standard material library

Table 3: Mechanical Properties of E-Glass/Epoxy

\begin{tabular}{|c|c|}
\hline Properties & Value \\
\hline $\begin{array}{c}\text { Tensile modulus along X-direction (Ex), } \\
\mathrm{Pa}\end{array}$ & $4.5 \mathrm{E}+10$ \\
$\mathrm{~Pa}$ & $1 \mathrm{E}+10$ \\
\hline $\begin{array}{c}\text { Tensile modulus along Y-direction (Ey), } \\
\text { Tensile modulus along Z-direction (Ez), Pa } \\
\mathrm{Pa}\end{array}$ & $1 \mathrm{E}+10$ \\
\hline $\begin{array}{c}\text { Shear modulus along XY-direction (Gxy), } \\
\mathrm{Pa}\end{array}$ & $5 \mathrm{E}+09$ \\
\hline \begin{tabular}{c} 
Shear modulus along YZ-direction (Gyz), \\
\hline
\end{tabular} & $3.8462 \mathrm{E}+09$ \\
\hline
\end{tabular}




\begin{tabular}{|c|c|}
\hline $\begin{array}{c}\text { Shear modulus along ZX-direction (Gzx), } \\
\mathrm{Pa}\end{array}$ & $5 \mathrm{E}+09$ \\
\hline Poisson ratio along XY-direction (NUxy) & 0.3 \\
\hline Poisson ratio along YZ-direction (NUyz) & 0.4 \\
\hline Poisson ratio along ZX-direction (NUzx) & 0.3 \\
\hline
\end{tabular}

Table 3: Shows the mechanical properties of composite (Carbon/Epoxy) material, which can be taken as per Ansys Standard material library.

Table 4 Mechanical Properties of Carbon/ Epoxy

\begin{tabular}{|c|c|}
\hline Properties & Value \\
\hline $\begin{array}{c}\text { Tensile modulus along X-direction } \\
\text { (Ex), Pa }\end{array}$ & $2.09 \mathrm{E}+11$ \\
\hline $\begin{array}{c}\text { Tensile modulus along Y-direction } \\
\text { (Ey), Pa }\end{array}$ & $9.45 \mathrm{E}+09$ \\
\hline $\begin{array}{c}\text { Tensile modulus along Z-direction } \\
\text { (Ez), Pa }\end{array}$ & $9.45 \mathrm{E}+09$ \\
\hline $\begin{array}{c}\text { Shear modulus along XY-direction } \\
\text { (Gxy), Pa }\end{array}$ & $5.5 \mathrm{E}+09$ \\
\hline $\begin{array}{c}\text { Shear modulus along YZ-direction } \\
\text { (Gyz), Pa }\end{array}$ & $3.9 \mathrm{E}+09$ \\
\hline $\begin{array}{c}\text { Shear modulus along ZX-direction } \\
\text { (Gzx), Pa }\end{array}$ & $5.5 \mathrm{E}+09$ \\
\hline $\begin{array}{c}\text { Poisson ratio along XY-direction } \\
\text { (NUxy) }\end{array}$ & 0.27 \\
\hline $\begin{array}{c}\text { Poisson ratio along YZ-direction } \\
\text { (NUyz) }\end{array}$ & 0.4 \\
\hline $\begin{array}{c}\text { Poisson ratio along ZX-direction } \\
\text { (NUzx) }\end{array}$ & 0.27 \\
\hline
\end{tabular}

The above mentioned three materials are used to perform the finite element analyses and compared with the conventional steel material for better improved mass and low stress and low total deformation.

\section{II.II BOUNDARY AND LOADING CONDITIONS}

The leaf spring is placed on the axle of the vehicle; the frame of the vehicle is attached to the ends (by eyes) of the leaf spring. The ends of the leaf spring are produced in the form of an eye. The front eye of the leaf spring is attached straightly with a pin to the frame so that the eye can revolve without restraint about the pin but no translation is takes place. The back eye of the spring is linked to the shackle which is a flexible link the next end of the shackle is linked to the frame of the vehicle. One eye of the leaf spring is reserved fixed (cylindrical support) and the other eye is given certain degree of rotation to allow the leaf spring to deflect by some amount along its length to meet the actual conditions for both the leaf spring (steel and composite) which is shown in Fig. below. After this load is applied of magnitude $3800 \mathrm{~N}$ in the upward direction at the centre of the PLS. This specific computation of load to be applied has been completed on the basis of Gross Vehicle Weight (GVW). This has been clearly shown the Fig. below.

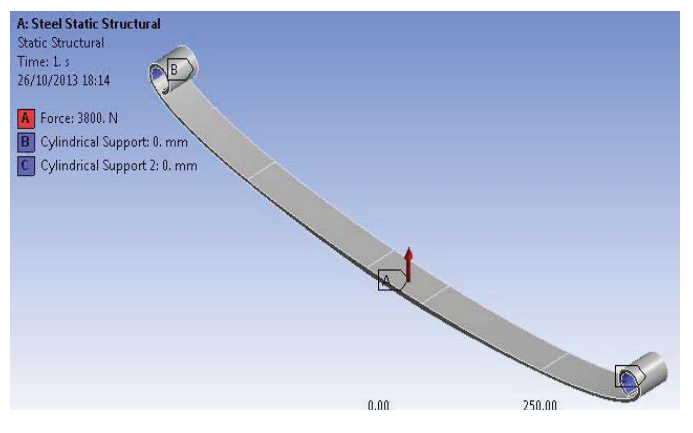

Fig. (1)

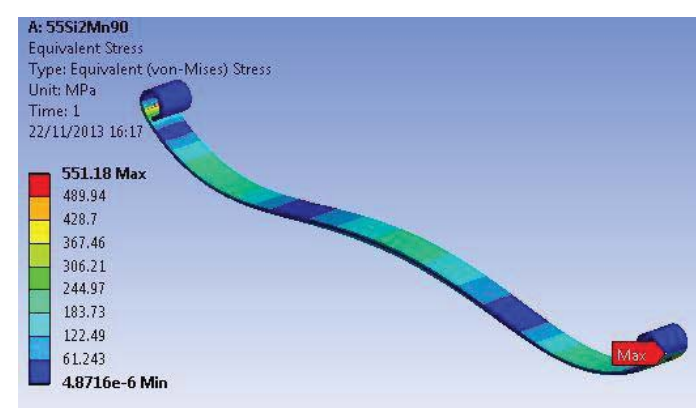

Fig. (2) 


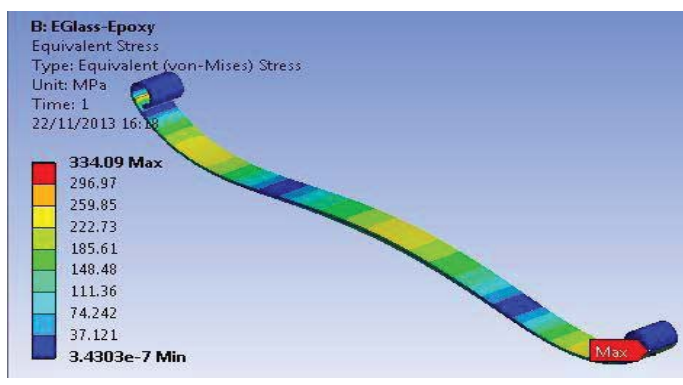

Fig. (3)

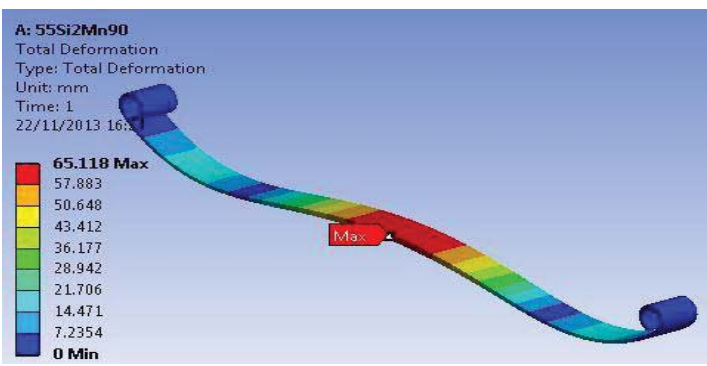

Fig. (5)

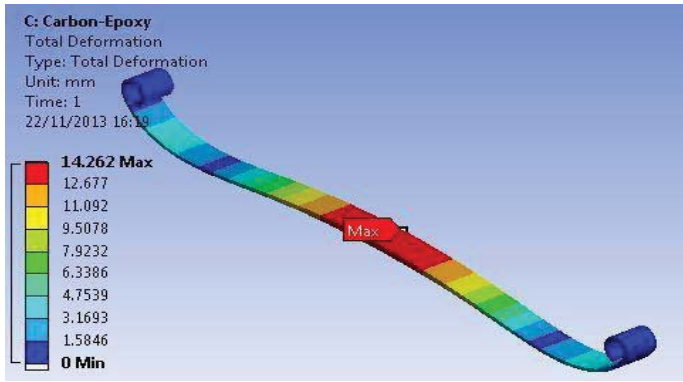

Fig. (7)

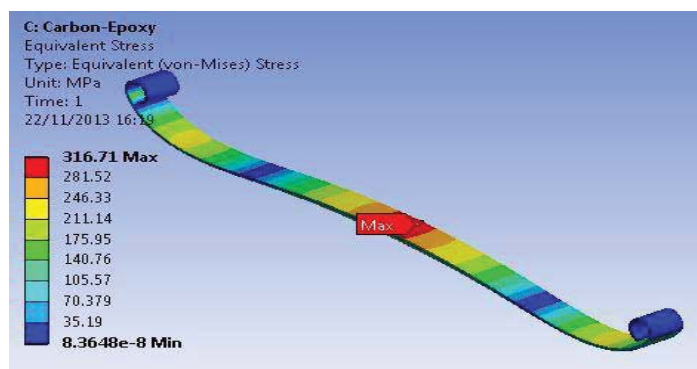

Fig. (4)

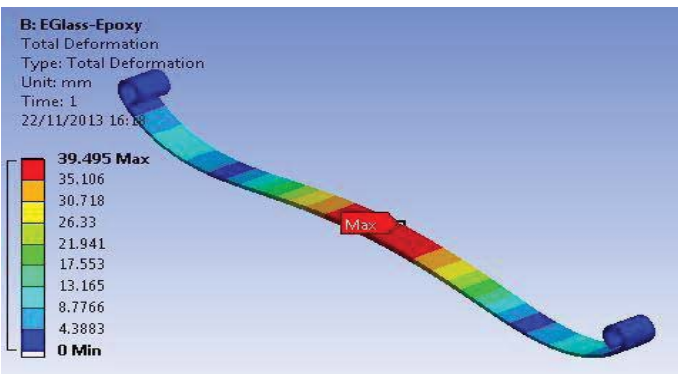

Fig. (6)

Fig. (1) Fig. (2) Fig. (3) Fig. (4) Fig. (5) Fig. (6) Fig. (7) Loading and boundary condition for leaf spring

The above result shows the improved strength and comfort level as low deflection for the leaf spring which is better in case of Carbon-Epoxy composite material, but we are still looking for the possible weight reduction. The mass of the conventional leaf spring is $4.613 \mathrm{~kg}$, EGlass-Epoxy composite leaf spring is measured as $1.175 \mathrm{~kg}$ and the mass for the Carbon-Epoxy composite leaf spring is measured as $0.905 \mathrm{~kg}$, which means Carbon-Epoxy composite leaf spring reduce the weight about $80 \%$ from conventional one.

\section{RESULTS AND DISCUSSION}

As presented above, we discussed the modeling and analyses of the conventional steel and three composite leaf springs with the same loading and boundary conditions. The results of the analyses are shown in the previous chapter. The results are tabulated in the Table Below.

Comparison between steel and three composite leaf springs 


\begin{tabular}{|l|c|c|c|c|}
\hline Parameter & $\begin{array}{l}\text { 55Si2Mn90 } \\
\text { steel leaf } \\
\text { spring }\end{array}$ & $\begin{array}{l}\text { E- } \\
\text { Glass/Epoxy } \\
\text { composite } \\
\text { leaf spring }\end{array}$ & $\begin{array}{l}\text { Carbon } \\
\text { Epoxy } \\
\text { prepreg }\end{array}$ & $\begin{array}{l}\text { Reduction } \\
\text { by Carbon } \\
\text { Epoxy } \\
\text { prepreg }\end{array}$ \\
\hline $\begin{array}{l}\text { Von-Mises } \\
\text { Stress } \\
\text { (MPa) }\end{array}$ & 450.73 & 338.03 & 316.71 & $30 \%$ \\
\hline $\begin{array}{l}\text { Total } \\
\text { Maximum } \\
\text { Deflection } \\
(\mathrm{mm})\end{array}$ & 65.118 & 39.495 & 14.262 & $78 \%$ \\
\hline $\begin{array}{l}\text { Total Mass } \\
(\mathrm{Kg})\end{array}$ & 4.613 & 1.175 & 0.905 & $80 \%$ \\
\hline
\end{tabular}
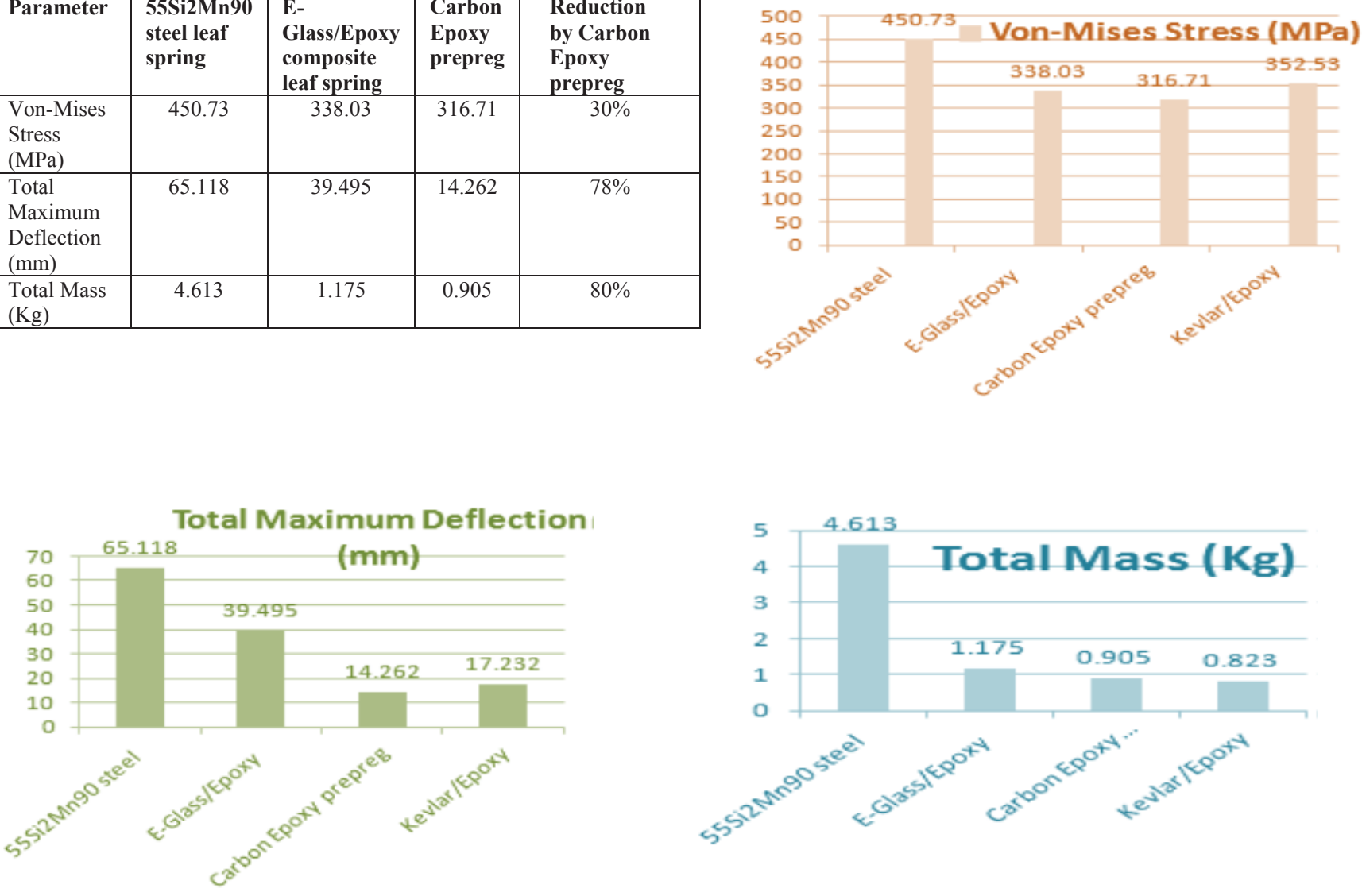

Comparison of four materials on basis of (a) Von-Mises Stress (b) Total Maximum Deflection (c) Total Mass

\section{CONCLUSION}

Under the same static load conditions deflection and stresses of steel leaf spring and composite leaf spring are found with the great difference. Deflection of Composite leaf spring is less as compared to steel leaf spring with the same loading condition. Conventional steel leaf spring was found to weigh $23 \mathrm{Kg}$. whereas E-Glass/Epoxy mono leaf spring weighs only3.59 Kg. Indicating reductions in weight by $80 \%$ in same level of performance. Conventional Leaf spring shows failure at eye end only. At maximum load condition also Composite Leaf Spring shows the minimum deflection as compared to Steel Leaf Spring. Composite leaf spring can be used on smooth roads with very high performance expectations.

\section{REFERENCES}

[1] Pankaj Saini, Ashish Goel and Dushyant Kumar, "design and analysis of composite leaf spring for light vehicles," International Journal of Innovative Research in Science, Engineering and Technology, Vol. 2, Issue 5, May 2013

[2] Shishay Amare Gebremeskel "Design, Simulation, and Prototyping of Single Composite Leaf Spring for Light Weight Vehicle" Global Journal of Researches in Engineering Mechanical and Mechanics Engineering Volume 12 Issue 7 Version 1.0 Year 2012 Online ISSN: 2249-4596 Print ISSN:0975-5861

[3] Jadhav Mahesh V, Zoman Digambar B, Y R Kharde, R R Kharde, "Performance Analysis of Two Mono Leaf Spring Used For Maruti 800 Vehicle", International Journal of Innovative Technology and Exploring Engineering (IJITEE) ISSN: 2278-3075, Volume-2, Issue-1, December 2012

[4] Shishay Amare Gebremeskel, "Design, Simulation, and Prototyping of Single Composite Leaf Spring for Light Weight Vehicle," Global Journal of Researches in Engineering Mechanical and Mechanics Engineering Volume 12 Issue 7 Version 1.0 Year 2012, Online ISSN: 2249-4596 Print ISSN:0975-5861

[5] Gulur Siddaramanna, Shiva Shankar, Sambagam Vijayarangan, "Mono Composite Leaf Spring for Light Weight Vehicle - Design, End Joint Analysis and Testing", ISSN 1392-1320 MATERIALS SCIENCE (MEDŽIAGOTYRA). Vol. 12, No. 3. 2006

[6] M.Joemax Agu and Gandhi V.C.Sathish, "Finite Element Analysis of Leaf Spring Considering The Nature of the Material", International Conference on Intelligent Science \& Technology, 2011.

[7] http://www.rolexmetals.com/sdp/191736/4/cp-4383676/0/Equivalent_Grades.html

[8] http://ace.tatamotors.com/ebrochure.php 
[9] R.S. Khurmi, J.K. Gupta." A text book of Machine Design, 2000"

[10] Deb, K., 2001, Multiobjective Optimization Using Evolutionary Algorithms, Wiley, New York.

[11] http://www.matweb.com/search/DataSheet.aspx?MatGUID=5fea5e82829a40218c5A864bdc865422\&ckck=1

[12] Kumar Krishan and Aggarwal M.L. "A Finite Element Approach for Analysis of a Multi Leaf Spring using CAE Tools", Research Journal of Recent Sciences, Vol. 1, pp. 92-96, December 2012.

[13] G. Wagle Sachin, Satish S. Oesai, Wadkar S. B., "Optimized Design \& Analysis of Parabolic Leaf Spring Considering Braking, Cornering \& Bump loads", National Conference of computational methods in Mechanical Engineering, pp. 47-52, September 2005.

[14] Materials Information (2002) retrieved June 182010 from University of Cambridge, Department of Engineering website: http://wwwmaterials.eng.cam.ac.uk/mpsite/interactive_charts/spec-spec/IEChart.html

[15] Belegundu, Ashok D and Chandrupatla, Tirupathi R. Optimization Concepts and Applications in Engineering. s. 1.: Pearson Education, 2005.

[16] J. Sacks, S. B. Schiller, W. J. Welch, "Design for computer experiments". Technometrics, 1989, Vol. 31, No. 1, pp. 41-47 